\title{
Chemoradiotherapy versus radiotherapy alone following induction chemotherapy for elderly patients with stage III lung cancer
}

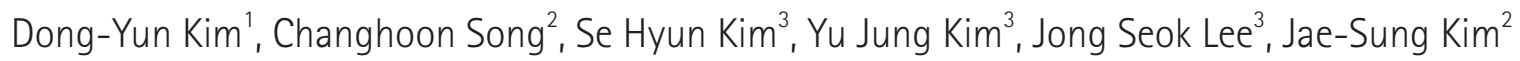 \\ 'Department of Radiation Oncology, Seoul National University Hospital, Seoul, Korea \\ ${ }^{2}$ Department of Radiation Oncology, Seoul National University Bundang Hospital, Seoul National University College of Medicine, \\ Seongnam, Korea \\ ${ }^{3}$ Department of Internal Medicine, Seoul National University Bundang Hospital, Seoul National University College of Medicine, \\ Seongnam, Korea
}

Purpose: It is unclear whether adding concurrent chemotherapy (CT) to definitive radiotherapy (RT) following induction CT is a tolerable and cost effective treatment for non-small-cell lung cancer (NSCLC) patients aged 70 years or older with comorbidities. This study evaluated the actual clinical outcomes between concurrent chemoradiotherapy (CCRT) and RT alone following induction CT or not in patients ( $\geq 70$ years) in a single institution's clinical practice.

Materials and Methods: A total of 82 patients with unresectable stage III NSCLC between 2004 and 2016 were retrospectively analyzed. Their treatment tolerance and clinical outcomes such as overall survival (OS), locoregional recurrence (LRR), treatment toxicities and distant metastasis (DM) were evaluated. Early mortality rates were also evaluated as 4-month mortality after RT.

Results: Fifty-four patients received CCRT and 28 patients received RT alone. Induction CT before RT was performed for $68.5 \%$ and $50.0 \%$ in CCRT and RT alone groups. Treatment tolerance was significantly worse in CCRT ( $p=0.046$ ). The median survival was 21.1 and 18.1 months for CCRT and RT alone, which was not statistically significant. LRR and DM were also not different. Most early deaths after CCRT were attributed to non-cancer-related mortality. Acute esophagitis of grade $\geq 2$ occurred more following CCRT ( $p$ $=0.017$ ). In multivariate analysis, a Charlson Comorbidity Index (CCI) of $\geq 5$ and a weight loss of $\geq 5 \%$ after RT were associated with poor OS. The factors adversely affecting 4 -month survival were a CCl of $\geq 5$ and CCRT.

Conclusion: There were no significant differences in OS, LRR, and DM between CCRT and RT alone treatment in elderly patients. However, there was a poorer tolerance and higher incidence of acute esophagitis in the CCRT group. Specifically, when the patients had a $\mathrm{CCl}$ of $\geq 5, \mathrm{RT}$ alone seems to be reasonable with a low probability of early death.

Keywords: Non-small cell lung cancer, Concurrent chemoradiotherapy, Induction chemotherapy, Radiotherapy, Aged 70 and over, Comorbidity

Introduction

Non-small-cell lung cancer (NSCLC) represents over $80 \%$ of all lung cancer cases, of which up to $35 \%$ are locally advanced

Received 07 February 2019, Revised 04 June 2019, Accepted 24 June 2019.

Correspondence: Jae-Sung Kim, Department of Radiation Oncology, Seoul National University Bundang Hospital, Seoul National University College of Medicine, 82 Gumi-ro 173beon-gil, Bundang-gu, Seongnam 13620, Korea. Tel: +82-31-7877652, Fax: +82-31-787-4019, E-mail: jskim@snubh.org (https://orcid.org/0000-0001-5348-9178)

(c) This is an Open Access article distributed under the terms of the Creative Commons Attribution Non-Commercial License (http://creativecommons.org/ licenses/by-nc/4.0/) which permits unrestricted non-commercial use, distribution, and reproduction in any medium, provided the original work is properly cited.

www.e-roj.org 


\section{ROJ Radiation Oncology Journal}

disease defined as stage III based on the American Joint Committee on Cancer (AJCC) 7th edition. For unresectable or medically inoperable stage III disease, concurrent chemoradiotherapy (CCRT) is considered a standard treatment; however, radiotherapy (RT) alone can be an alternative option [1]. Although the median age of patients newly diagnosed with NSCLC is 70 years old [2], the current evidence for a standard treatment regimen is mainly based on relatively fit and nongeriatric patients [1]. In addition, patients with NSCLC older than 70 years generally have a poor performance status and concomitant comorbidities; thus, the treatment goals for them should take into consideration not only cancer control but also treatment tolerance and quality of life.

Several recent studies involving elderly patients with stage III NSCLC have shown that the effects of CCRT and RT alone on overall survival (OS) are conflicting. In the phase III Japan Clinical Oncology Group (JCOG) 0301 randomized trial, the patients were randomly assigned to RT alone or CCRT (same radiotherapy with $\mathrm{RT}$ alone group, with additional concurrent use of carboplatin). A recent update from long-term follow-up published in 2017 revealed CCRT showed the survival benefits without increasing the late toxicity compared to RT alone $[3,4]$. However, a multicenter retrospective study from the Netherlands Cancer Registry revealed no differences in survival among treatments with CCRT, sequential chemoradiotherapy, and RT alone [1]. On the other hand, a meta-analysis by a Canadian study group found that improved OS was associated with CCRT compared with RT alone [5]. Since there were heterogeneous patient characteristics and different treatments such as neoadjuvant or adjuvant chemotherapy (CT) in each study according to the institution, optimal guidelines for the treatment decision for elderly patients are limited and need to be investigated further $[6,7]$. In our institution, if patients can tolerate $\mathrm{CT}$ at the clinician's discretion, at least 2 cycles of induction CT were performed, and they were reevaluated for CCRT or RT alone. In comparison with previous studies, the major difference in this study was that the proportion of induction CT was higher up to $62.2 \%$.

We aimed to evaluate the actual clinical outcomes between patients with NSCLC ( $\geq 70$ years) who received CCRT and those who received RT alone and identify the factors affecting the OS and early mortality after RT.

\section{Methods}

\section{Patients}

After the approval of the Institutional Review Board of Seoul
CCRT vs RT alone following induction CT for elderly NSCLC

National University Bundang Hospital (No. B-1804/465304), we retrospectively analyzed 82 patients aged 70 years or older with stage III NSCLC treated at Seoul National University Bundang Hospital between 2004 and 2016. The inclusion criteria were as follows: (1) unresectable or medically inoperable histologically proven stage III NSCLC (AJCC 7th edition); (2) curative-intent treatment with RT; and (3) radiation dose of at least $54 \mathrm{~Gy}$ with a biologically effective dose at $2 \mathrm{~Gy}$ per fraction $\left(\mathrm{BED}_{2}\right)$.

The concomitant comorbidities were scored with the Charlson Comorbidity Index (CCI), which has been widely used to measure comorbid disease status and predict mortality due to comorbid disease burden [8].

\section{Treatments}

Radiotherapy was administered with 6-15 MV photons from a linear accelerator using either a 3-dimensional conformal technique $(n=72)$ or intensity-modulated radiotherapy $(n=$ 10). Simulation CT was performed with guiding the patients to perform quiet respiration during simulation. The target volume for RT planning included the gross tumor volume (GTV) and the involved lymph node areas only, without elective nodal irradiation. The clinical target volume (CTV) covered the GTV plus extra margin to include areas at risk of microscopic extension. And the planning target volume was defined to include the inter- and intra-fractional motion as CTV plus a 10-15 mm margin.

As different schedules were used, the total radiation dose was calculated as the $\mathrm{BED}_{2}$ for comparison. The most commonly used schedule was 66 Gy with 33 fractions. The median $\mathrm{BED}_{2}$ was 63.6 Gy (range, 48.0 to 70.9 Gy). The treatment groups were grossly classified as CCRT and RT alone. If a patient received $C T$ simultaneously at the time of $R T$, we categorized it as 'CCRT', and 'RT alone' was defined as treatment with only a single modality of radiation, independent of induction or consolidation CT.

In our institution, the patients diagnosed with stage III NSCLC and assessed to be initially medically inoperable were usually referred to the medical oncologist for induction CT, at first. After induction $\mathrm{CT}$, surgical resection or definitive thoracic RT was considered as a local treatment modality by clinical response of the induction CT. After CCRT or RT alone, some patients were treated with the consolidation CT at the discretion of each hemato-oncologist's opinion. Overall, 62.2\% (51/82) of patients received induction CT, and 15.9\% (12/82) of patients received consolidation $\mathrm{CT}$. The regimens of induction CT were gemcitabine-paclitaxel $(n=27)$, docetaxel-cisplatin 


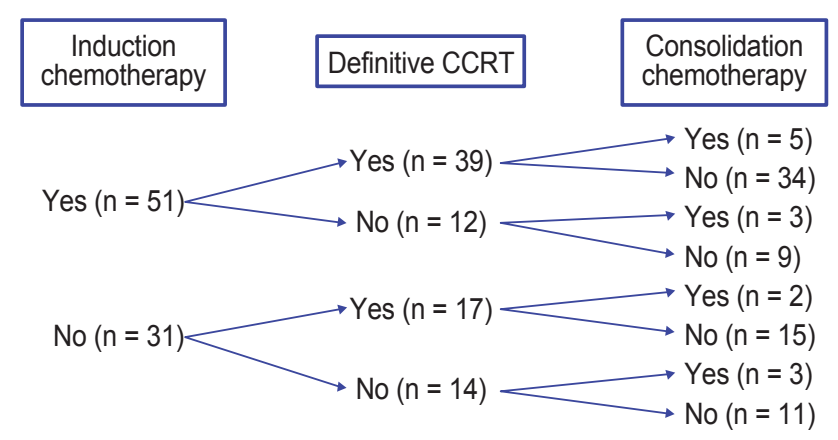

Fig. 1. Details of treatment including induction and consolidation chemotherapy. CCRT, concurrent chemoradiotherapy.

( $n=19)$, and others $(n=5)$. Most patients $(66.7 \%)$ received 2 to 3 cycles of the induction CT ( $n=16$ for 2 cycles, $n=18$ for 3 cycles). There were 17 patients for 4 cycles or more of induction CT ( 4 to 8 cycles). The regimens of concurrent CT were paclitaxel-cisplatin $(n=48)$, docetaxel-cisplatin $(n=3)$, and others $(n=3)$. The regimens of consolidation CT were also heterogeneous, which were docetaxel-cisplatin $(n=2)$, gemcitabine-cisplatin $(n=2)$, docetaxel alone $(n=2)$, multiple chemotherapy $(n=4)$ and clinical trial $(n=2)$. Details of the treatment scheme were summarized in Fig. 1.

\section{Definition of treatment tolerance and base of follow- up date}

Patients were regarded as having treatment tolerance if they had no unintended breaks for more than 5 days during RT, or were not hospitalized for grade 3 or higher toxicities. Unintended breaks are defined as RT breaks due to aggravated performance status or low absolute neutrophil count levels on regular complete blood count examinations, as compared to the intended break due to personal circumstances not associated with patient's condition or acute side effects. For the clinical outcome analysis, the date of base of followup was set to the start of RT. In addition, to analyze the early mortality rate, the survival rate within 4 months after treatment (4-month mortality) was calculated from the last date of RT. The treatment toxicity was graded based on Common Terminology Criteria for Adverse Events (CTCAE) version 4.0.

\section{Statistical analysis}

The chi-square test was used for comparing treatment tolerance and patient characteristics between the two treatment groups (CCRT and RT alone). We analyzed factors affecting $O S$ and 4-month survival using a stepwise Cox regression model. OS, 4-month survival, locoregional recurrence (LRR), and distant metastasis (DM) were examined using the Kaplan-Meier method, and the p-value was calculated by the log-rank test. All analyses were performed using Stata/MP 15.0 (StataCorp., College Station, TX, USA) with a significance level of $<0.05$.

\section{Results}

A total of 82 patients aged 70 years or older with unresectable stage III NSCLC were analyzed. The median follow-up time for the surviving patients was 20.1 months (range, 0.2 to 91.8 months). We analyzed patients according to the treatment groups CCRT ( $n=54,65.9 \%)$ and RT alone $(n=28,34.1 \%)$. The median age of the CCRT and RT alone group was 73.0 years and 75.2 years, respectively, which was significantly different $(p=0.016)$. The demographics of the patients are shown in Table 1. There was no difference in the performance status, $\mathrm{CCl}$, pre-RT body mass index, and clinical stage between the CCRT and RT alone group. Induction CT was performed for $68.5 \%$ of patients in the CCRT group and $50.0 \%$ of patients in the RT alone group. The median dose $\left(\mathrm{BED}_{2}\right)$ was $63.5 \mathrm{~Gy}$ (range, 48.0 to $70.9 \mathrm{~Gy}$ ) for the CCRT group and $63.7 \mathrm{~Gy}$ (range, 55.3 to $70.0 \mathrm{~Gy}$ ) for the RT alone group. In the CCRT group, the number of patients who had a weight loss of $\geq 5 \%$ after RT was significantly higher $(p=0.031)$. Particularly, the treatment tolerance was significantly worse in the CCRT group (87.0\%) than in the RT alone group (100.0\%) $(p=0.046)$ (Table 2).

The median survival was 21.1 months and 18.1 months for the CCRT and RT alone group, respectively, which was not statistically significant ( $p=0.220$ ) (Fig. 2). LRR and DM were also not significantly different between the two treatment groups ( $p=0.897$ for $L R R, p=0.485$ for $D M$ ). Although there was no statistical significance, the survival rate within 4 months after RT (4-month survival) was higher in the RT alone group than in the CCRT group, which was $89.3 \%$ and $79.6 \%$ respectively $(p=0.230)$. The mortality rate within 4 months was $20.4 \%(n=11)$ in the CCRT group and $10.7 \%(n=3)$ in the RT alone group. The causes of 4-month mortality in the CCRT group were as follows: pneumonia (7 patients), neutropenia (1 patient), acute cerebral infarction (1 patient), and unknown causes (2 patients). In the RT alone group, one died from disease progression, and the other two died from aggravated general conditions without exact causes. As a result, most deaths in the CCRT group were attributed to non-cancerrelated mortality such as pneumonia, and the rate of early death within 4 months after RT was around two times higher 
Table 1. Patients' characteristics $(n=82)$

\begin{tabular}{|c|c|c|c|}
\hline & CCRT $(n=54)$ & RT alone $(n=28)$ & $p$-value \\
\hline \multicolumn{4}{|l|}{ Age (yr) } \\
\hline $70-74$ & $40(74.1)$ & $12(42.9)$ & \multirow[t]{3}{*}{$0.016^{6}$} \\
\hline $75-79$ & $11(20.4)$ & $12(42.2)$ & \\
\hline$\geq 80$ & $3(5.5)$ & $4(14.2)$ & \\
\hline \multicolumn{4}{|l|}{ Gender } \\
\hline Male & 48 (88.9) & 25 (89.3) & \multirow[t]{2}{*}{$0.957^{\mathrm{a}}$} \\
\hline Female & $6(11.1)$ & $3(10.7)$ & \\
\hline \multicolumn{4}{|c|}{ ECOG performance status } \\
\hline $0-1$ & 19 (35.2) & $9(32.1)$ & \multirow[t]{2}{*}{$0.783^{\mathrm{a}}$} \\
\hline $2-4$ & $35(64.8)$ & $19(67.9)$ & \\
\hline \multicolumn{4}{|c|}{ Charlson Comorbidity Index } \\
\hline $2-4$ & $43(79.6)$ & $20(71.4)$ & \multirow[t]{2}{*}{$0.404^{a}$} \\
\hline $5-8$ & $11(20.4)$ & $8(28.6)$ & \\
\hline \multicolumn{4}{|l|}{ Pre-RT BMI } \\
\hline$<22$ & $24(44.4)$ & $16(57.1)$ & \multirow[t]{2}{*}{$0.275^{\mathrm{a}}$} \\
\hline$\geq 22$ & $30(55.6)$ & $12(42.9)$ & \\
\hline \multicolumn{4}{|l|}{ History of smoking } \\
\hline Yes & $48(88.9)$ & 25 (89.3) & \multirow[t]{2}{*}{$0.957^{\mathrm{a}}$} \\
\hline No & $6(11.1)$ & $3(10.7)$ & \\
\hline \multicolumn{4}{|l|}{ Histology } \\
\hline$A D C$ & $9(16.7)$ & $7(25.9)$ & \multirow[t]{3}{*}{$0.603^{\mathrm{a}}$} \\
\hline $\mathrm{SqCC}$ & $35(64.8)$ & $17(59.3)$ & \\
\hline Others+ & $10(18.5)$ & $4(14.8)$ & \\
\hline \multicolumn{4}{|l|}{ Stage } \\
\hline$\| \mathrm{A}$ & $35(64.8)$ & $21(75.0)$ & \multirow[t]{2}{*}{$0.347^{\mathrm{a}}$} \\
\hline IIIB & $19(35.2)$ & $7(25.0)$ & \\
\hline \multicolumn{4}{|l|}{ T stage } \\
\hline $\mathrm{T} 1 / \mathrm{T} 2$ & $23(42.6)$ & $12(42.9)$ & \multirow[t]{2}{*}{$0.982^{\mathrm{a}}$} \\
\hline T3/T4 & $31(57.4)$ & $16(57.1)$ & \\
\hline \multicolumn{4}{|l|}{ N stage } \\
\hline No/N1 & $9(16.7)$ & $5(17.9)$ & \multirow[t]{3}{*}{$0.735^{2}$} \\
\hline N2 & $27(50.0)$ & $16(57.1)$ & \\
\hline N3 & 18 (33.3) & $7(25.0)$ & \\
\hline \multicolumn{4}{|c|}{ Induction chemotherapy } \\
\hline Yes & $37(68.5)$ & $14(50.0)$ & \multirow[t]{2}{*}{$0.101^{a}$} \\
\hline No & $17(31.5)$ & $14(50.0)$ & \\
\hline \multicolumn{4}{|c|}{ Consolidation chemotherapy } \\
\hline Yes & $6(11.1)$ & $6(21.4)$ & \multirow[t]{2}{*}{$0.320^{\mathrm{a}}$} \\
\hline No & $48(88.9)$ & $22(78.6)$ & \\
\hline Total dose $\left(\mathrm{BED}_{2}\right)$ & $63.5 \pm 5.0(48.0-70.9)$ & $63.7 \pm 3.6(55.3-70.0)$ & $0.542^{c}$ \\
\hline \multicolumn{4}{|c|}{ Weight loss $\geq 5 \%$ after RT } \\
\hline Yes & $17(31.5)$ & $2(7.1)$ & $0.031^{\mathrm{a}}$ \\
\hline No & $37(68.5)$ & $26(92.9)$ & \\
\hline
\end{tabular}

Values are presented as number (\%) or mean \pm standard deviation.

ECOG, Eastern Cooperative Oncology Group; RT, radiotherapy; BMI, body mass index; ADC, adenocarcinoma; SqCC, squamous cell carcinoma; Others+, large cell neuroendocrine carcinoma, poorly differentiated carcinoma; BED, biologically effective dose at 2 Gy per fraction.

${ }^{a)}$ Chi-square test, ${ }^{\text {b) }}$ isher exact test, and ${ }^{\mathrm{c}}$ Mann-Whitney U test. 
Table 2. Causes of 4-month mortality after radiotherapy by the treatment modality

\begin{tabular}{lcc}
\hline & CCRT $(\mathrm{n}=54)$ & $\mathrm{RT}$ alone $(\mathrm{n}=28)$ \\
\hline Treatment tolerance (\%) & 87.0 & 100 \\
4-month death patients & $11(20.4)$ & $3(10.7)$ \\
Causes of 4-month mortality & 0 & 1 \\
Disease progression & 7 & 0 \\
Pneumonia & 1 & 0 \\
Neutropenia & 1 & 0 \\
Acute cerebral infarction & 2 & 2 \\
Unknown or aggravation of general condition & & \\
\hline
\end{tabular}

Values are presented as number (\%).

CCRT, concurrent chemoradiotherapy; RT, radiotherapy.

in the CCRT group than in the RT alone group (Table 2). These results suggested that the addition of $\mathrm{CT}$ to definitive RT might increase the incidence of early death due to causes other than lung cancer itself. Therefore, it was necessary to analyze the risk factors to find out the patients who did not benefit from CCRT to reduce early death within 4 months after RT.

Toxicity analysis revealed that acute esophagitis of grade 2 or higher occurred more frequently in the CCRT group than in the RT alone group ( $p=0.017$ ). Grade 2 or higher acute esophagitis was observed for 24 patients (44.4\%) in the CCRT group and 5 patients (17.9\%) in the RT alone group. However, there was no significant difference in the incidence of grade 3-4 radiation pneumonitis between the two treatment groups, which was 10 patients (18.5\%) in the CCRT group and 4 patients $(14.3 \%)$ in the RT alone group ( $p=0.629)$.

Clinical factors associated with OS and 4-month survival were evaluated by univariate and multivariate analyses with the stepwise Cox regression model. In multivariate analysis, OS was significantly associated with a $\mathrm{CCl}$ of $\geq 5$ (hazard ration $[\mathrm{HR}]=2.00 ; 95 \%$ confidence interval $[\mathrm{Cl}], 1.10-3.61 ; \mathrm{p}=0.022)$ and a weight loss of $\geq 5 \%$ after treatment $(\mathrm{HR}=2.46 ; 95 \% \mathrm{Cl}$, $1.33-4.54 ; p=0.004$ ) (Table 3 ). The factors adversely affecting 4-month survival were also a $\mathrm{CCl}$ score of $\geq 5(\mathrm{HR}=6.46$; $95 \% \mathrm{Cl}, 2.18-19.21 ; p=0.001)$ and treatment modality (HR $=3.91 ; 95 \% \mathrm{Cl}, 1.02-14.93 ; \mathrm{p}=0.047$ ) (Table 4). Furthermore, among patients with a $\mathrm{CCl}$ score of $\geq 5, \mathrm{RT}$ alone resulted in significantly better survival compared with CCRT at 4 months of follow-up ( $p=0.038)$. In the CCRT group, 11 patients died within 4 months after RT; however, only three deaths were observed in the RT alone group.

\section{Discussion and Conclusion}

The purpose of this study was to evaluate actual clinical

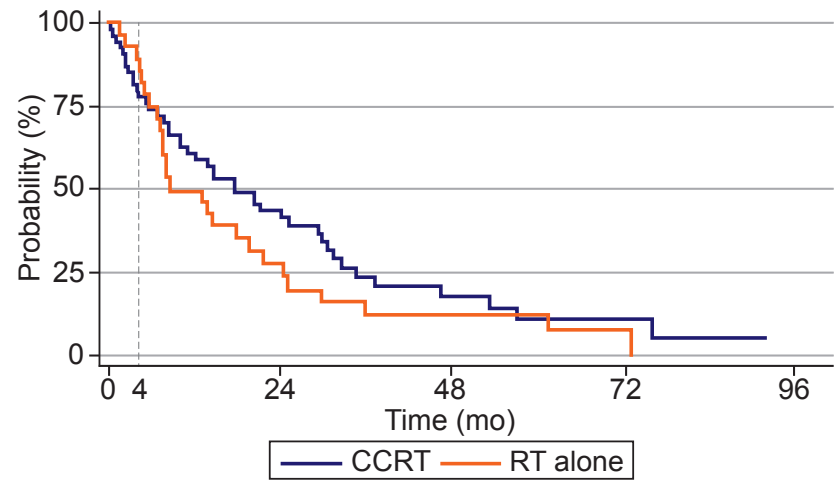

Fig. 2. Actuarial overall survival curves of patients who received CCRT and RT alone ( $p=0.230$ by log-rank test). CCRT, concurrent chemoradiotherapy; $\mathrm{RT}$, radiotherapy.

outcomes between CCRT and RT alone for patients older than 70 years who were diagnosed with locally advanced NSCLC in a single institution with a relatively high rate of induction $\mathrm{CT}$ given. CCRT is widely known as the standard treatment for stage III NSCLC [9-11]. However, it is unclear whether CCRT is a tolerable and cost effective treatment option for elderly patients with accompanying comorbidities over the age of 70 years.

In previous studies, there were conflicting results about which treatment options (CCRT or RT alone) would be suitable for elderly patients with stage III NSCLC. A phase III JCOG 0301 trial and meta-analysis by a Canadian study group showed the survival benefit of CCRT compared to the RT alone treatment, though toxicities increased [3-5]. However, a multicenter retrospective study based on the Netherlands Cancer Registry showed no differences in survival among treatments with poorer tolerance to chemoradiotherapy, especially for those with severe comorbidities [1]. In addition, Miller et al. showed that sequential CT and RT were superior to other modalities 
Table 3. Univariate and multivariate analysis of risk factor for overall survival

\begin{tabular}{|c|c|c|c|c|c|}
\hline & \multirow{2}{*}{$\begin{array}{c}\text { No. of } \\
\text { patients }\end{array}$} & \multicolumn{2}{|c|}{ Univariate analysis } & \multicolumn{2}{|c|}{ Multivariate analysis } \\
\hline & & HR $(95 \% \mathrm{Cl})$ & $p$-value $e^{a)}$ & HR $(95 \% \mathrm{Cl})$ & $p$-value \\
\hline \multicolumn{6}{|l|}{ Age (yr) } \\
\hline $70-74$ & 52 & 1 & & - & \\
\hline $75-79$ & 23 & $1.26(0.72-2.19)$ & 0.418 & - & \\
\hline$\geq 80$ & 7 & $1.88(0.83-4.24)$ & 0.128 & - & \\
\hline \multicolumn{6}{|l|}{ Gender } \\
\hline Male & 73 & 1 & & - & \\
\hline Female & 9 & $0.40(0.17-0.91$ & 0.030 & $0.52(0.21-1.25)$ & 0.143 \\
\hline \multicolumn{6}{|c|}{ ECOG performance status } \\
\hline $0-1$ & 28 & 1 & & - & \\
\hline $2-4$ & 54 & $0.90(0.54-1.51)$ & 0.693 & - & \\
\hline \multicolumn{6}{|c|}{ Charlson Comorbidity Index } \\
\hline $2-4$ & 63 & 1 & & - & \\
\hline $5-8$ & 19 & $2.20(1.26-3.85)$ & 0.006 & $2.00(1.10-3.61)$ & 0.022 \\
\hline \multicolumn{6}{|c|}{ Pre-RT BMI } \\
\hline$<22$ & 40 & 1 & & - & \\
\hline$\geq 22$ & 42 & $0.89(0.55-1.44)$ & 0.628 & - & \\
\hline \multicolumn{6}{|c|}{ Weight loss $\geq 5 \%$ after RT } \\
\hline No & 63 & 1 & & - & \\
\hline Yes & 19 & $2.15(1.20-3.82)$ & 0.009 & $2.46(1.33-4.54)$ & 0.004 \\
\hline \multicolumn{6}{|c|}{ History of smoking } \\
\hline No & 9 & 1 & & - & \\
\hline Yes & 73 & $1.18(0.51-2.72)$ & 0.706 & - & \\
\hline \multicolumn{6}{|l|}{ Histology } \\
\hline$A D C$ & 16 & 1 & & - & \\
\hline $\mathrm{SqCC}$ & 52 & $0.89(0.49-1.61)$ & 0.699 & - & \\
\hline Others+ & 14 & $0.84(0.38-1.89)$ & 0.679 & - & \\
\hline \multicolumn{6}{|l|}{ Stage } \\
\hline IIIA & 56 & 1 & & - & \\
\hline$\| \mathrm{B}$ & 26 & $1.12(0.66-1.90)$ & 0.667 & $0.15(0.02-1.26)$ & 0.080 \\
\hline \multicolumn{6}{|l|}{ T stage } \\
\hline $\mathrm{T} 1 / \mathrm{T} 2$ & 35 & 1 & & - & \\
\hline $\mathrm{T} 3 / \mathrm{T} 4$ & 47 & $0.86(0.53-1.40)$ & 0.538 & - & \\
\hline \multicolumn{6}{|l|}{$N$ stage } \\
\hline No/N1 & 14 & 1 & & - & \\
\hline N2 & 43 & $0.95(0.49-1.84)$ & 0.885 & - & \\
\hline N3 & 25 & $1.02(0.49-2.10)$ & 0.962 & $0.20(0.02-1.71)$ & 0.142 \\
\hline \multicolumn{6}{|c|}{ Treatment modality } \\
\hline CCRT & 54 & 1 & & - & \\
\hline RT alone & 28 & $1.36(0.83-2.22)$ & 0.222 & $1.56(0.93-2.64)$ & 0.097 \\
\hline \multicolumn{6}{|c|}{ Induction chemotherapy } \\
\hline No & 31 & 1 & & - & \\
\hline Yes & 51 & $0.75(0.46-1.22)$ & 0.247 & - & \\
\hline \multicolumn{6}{|c|}{ Consolidation chemotherapy } \\
\hline No & 70 & 1 & & - & \\
\hline Yes & 12 & $0.63(0.33-1.23)$ & 0.176 & - & \\
\hline
\end{tabular}

ECOG, Eastern Cooperative Oncology Group; RT, radiotherapy; BMI, body mass index; ADC, adenocarcinoma; SqCC, squamous cell carcinoma; Others+, large cell neuroendocrine carcinoma, poorly differentiated carcinoma.

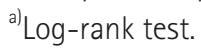


Table 4. Univariate and multivariate analysis of risk factor for 4-month survival

\begin{tabular}{|c|c|c|c|c|c|}
\hline & \multirow{2}{*}{$\begin{array}{c}\text { No. of } \\
\text { patients }\end{array}$} & \multicolumn{2}{|c|}{ Univariate analysis } & \multicolumn{2}{|c|}{ Multivariate analysis } \\
\hline & & $\mathrm{HR}(95 \% \mathrm{Cl})$ & $p$-value $e^{a)}$ & $\mathrm{HR}(95 \% \mathrm{Cl})$ & $p$-value \\
\hline \multicolumn{6}{|l|}{ Age (yr) } \\
\hline $70-74$ & 52 & 1 & & - & \\
\hline $75-79$ & 23 & $1.50(0.49-4.58)$ & 0.477 & - & \\
\hline$\geq 80$ & 7 & $1.86(0.11-6.90)$ & 0.128 & $2.35(0.74-7.48)$ & 0.149 \\
\hline \multicolumn{6}{|l|}{ Gender } \\
\hline Male & 73 & 1 & & - & \\
\hline Female & 9 & $N / A$ & 1.000 & - & \\
\hline \multicolumn{6}{|c|}{ ECOG performance status } \\
\hline $0-1$ & 28 & 1 & & - & \\
\hline $2-4$ & 54 & $0.52(0.18-1.47)$ & 0.217 & - & \\
\hline \multicolumn{6}{|c|}{ Charlson Comorbidity Index } \\
\hline $2-4$ & 63 & 1 & & - & \\
\hline $5-8$ & 19 & $5.47(1.89-15.81)$ & 0.002 & $6.46(2.18-19.21)$ & 0.001 \\
\hline \multicolumn{6}{|c|}{ Pre-RT BMI } \\
\hline$<22$ & 40 & 1 & & - & \\
\hline$\geq 22$ & 42 & $0.49(0.17-1.47)$ & 0.205 & $0.39(0.12-1.21)$ & 0.101 \\
\hline \multicolumn{6}{|c|}{ Weight loss $\geq 5 \%$ after RT } \\
\hline No & 63 & 1 & & - & \\
\hline Yes & 19 & $2.17(0.73-6.49)$ & 0.165 & & \\
\hline \multicolumn{6}{|c|}{ History of smoking } \\
\hline No & 9 & 1 & & - & \\
\hline Yes & 73 & $0.45(0.13-1.61)$ & 0.221 & - & \\
\hline \multicolumn{6}{|l|}{ Histology } \\
\hline$A D C$ & 16 & 1 & & - & \\
\hline $\mathrm{SqCC}$ & 52 & 1.07 (0249-3.88) & 0.922 & - & \\
\hline Others+ & 14 & $0.36(0.04-3.47)$ & 0.377 & - & \\
\hline \multicolumn{6}{|l|}{ Stage } \\
\hline IIIA & 56 & 1 & & - & \\
\hline IIIB & 26 & $0.55(0.15-1.96)$ & 0.354 & $2.64(0.63-11.16)$ & 0.186 \\
\hline \multicolumn{6}{|l|}{ T stage } \\
\hline $\mathrm{T} 1 / \mathrm{T} 2$ & 35 & 1 & & - & \\
\hline T3/T4 & 47 & $1.39(0.47-4.16)$ & 0.552 & - & \\
\hline \multicolumn{6}{|l|}{ N stage } \\
\hline No/N1 & 14 & 1 & & - & \\
\hline N2 & 43 & $0.85(0.23-3.18)$ & 0.820 & - & \\
\hline N3 & 25 & $0.31(0.05-1.88)$ & 0.204 & - & \\
\hline \multicolumn{6}{|c|}{ Treatment modality } \\
\hline RT alone & 28 & 1 & & & \\
\hline CCRT & 54 & $2.04(0.56-7.14)$ & 0.277 & 3.91 (1.02-14.93) & 0.047 \\
\hline \multicolumn{6}{|c|}{ Induction chemotherapy } \\
\hline No & 31 & 1 & & - & \\
\hline Yes & 51 & $0.57(0.20-1.63)$ & 0.297 & $0.42(0.14-1.32)$ & 0.140 \\
\hline \multicolumn{6}{|c|}{ Consolidation chemotherapy } \\
\hline No & 70 & 1 & & - & \\
\hline Yes & 12 & $0.37(0.05-2.82)$ & 0.337 & - & \\
\hline
\end{tabular}

ECOG, Eastern Cooperative Oncology Group; RT, radiotherapy; BMI, body mass index; ADC, adenocarcinoma; SqCC, squamous cell carcinoma; Others+, large cell neuroendocrine carcinoma, poorly differentiated carcinoma.

a) Log-rank test. 


\section{ROJ Radiation Oncology Journal}

in terms of survival benefit [6]. As such, each study was comprised of patients with heterogeneous characteristics and different treatments, so the optimal strategy for unresectable NSCLC in elderly patients is still inconclusive.

Although CCRT is considered as a treatment of choice in cases of locally advanced NSCLC, a few institutions have treated patients with induction CT followed by CCRT or RT alone [12-15]. Induction CT has been performed for the downstaging of the disease, the treatment of systemic microscopic metastasis, and a better drug delivery to the tumor [16]. A previous study showed that patients treated with platinum/ taxane-based induction CT in addition to RT for unresectable NSCLC had a better OS than that of patients treated with RT alone [13]. In addition, a meta-analysis by Luo et al. revealed an improvement in the 5-year OS from induction CT followed by CCRT compared with CCRT alone for patients with locally advanced NSCLC; however, there was no significant difference compared with consolidation $\mathrm{CT}$ for patients treated with CCRT [16]. In a phase III PITCAP trial, 151 patients were randomized to receive 2 cycles of platinum-paclitaxel induction CT followed by thoracic RT only vs. CCRT. The results of the study showed no survival benefit with the addition of concurrent CT with RT compared with RT alone after induction CT. Although the median age of the patients was 61 years, which was younger than that in our study, this randomized phase III trial demonstrated the possibility of omitting concurrent CT after induction CT [14].

This study included only patients older than 70 years with stage III NSCLC for analyzing clinical outcomes. In comparison with other studies, a characteristic feature was that the rate of induction CT was as high as $62.2 \%$. We categorized treatments as CCRT or RT alone based on whether RT was performed simultaneously with CT or alone, regardless of the implementation of induction or consolidation CT. In our study, there were no significant differences in OS, LRR, and DM between the two treatment modalities. Moreover, we demonstrated that OS and 4-month survival were adversely associated with a $\mathrm{CCl}$ of $\geq 5$. As mentioned previously, the $\mathrm{CCl}$ has been widely used to measure concomitant comorbidities and predict mortality due to comorbid disease burden. Elderly patients usually have a few underlying medical diseases. However, because of the different proportions of medically fit old patients included, the clinical results of previous studies involving elderly patients with stage III NSCLC may be inconsistent. Therefore, we should classify elderly patients according to the $\mathrm{CCl}$, which is reliable and easy to apply in a clinical practice, and classify them as medically fit or unfit.
CCRT vs RT alone following induction CT for elderly NSCLC

The scoring of patient comorbidities by the $\mathrm{CCl}$ needs to be considered when deciding treatment options for elderly patients based on treatment tolerance. In addition, a balance between tumor control, treatment tolerance, and expected survival should be considered in the treatment of elderly patients. The results of this study showed that most patients died within 4 months after RT were due to other reasons without evidence of LRR or DM. The mortality rate within 4 months was 20.4\% (11 cases) for CCRT and 10.7\% (3 cases) for RT alone. The 4-month mortality in the CCRT group was around two times higher compared with that in the RT alone group, and most causes of the 4-month mortality in the CCRT group were associated with non-cancer-related diseases such as pneumonia, neutropenia, or abrupt aggravation of general conditions without cancer progression. Therefore, even if the tumor is locally controlled, it is doubtful that CCRT is beneficial for elderly patients if they die early after treatment. Moreover, our study revealed that CCRT resulted in a higher incidence of grade 2 or higher acute esophagitis, indicating poorer tolerance and unfavorable quality of life. Patients who received CCRT had a weight loss of $\geq 5 \%$ after RT more than RT alone group. Considering that a weight loss of $\geq 5 \%$ after RT significantly affected OS, nutritional support may be needed to reduce the mortality of elderly patients during CCRT [17].

This study basically has several limitations. Due to the retrospective nature, it has an inherent weakness of selection bias when choosing induction or consolidation CT based on patient characteristics. Because elderly patients referred to RT were selected according to the judgment of the hematooncologist, those treated with induction CT might be relatively fit considering their age even if they had several comorbidities. In addition, the sample size was not sufficient to confirm the results. Nevertheless, the results in the present study were clinically significant because it showed a single institutional treatment outcome with a high proportion of induction CT. As the current standard of care for unresectable stage III NSCLC is CCRT, previous studies in which CCRT was performed after induction CT are limited. This study also demonstrated similar overall clinical outcomes such as the median OS of elderly patients in the CCRT and RT alone group. The classification of aged patients by the $\mathrm{CCl}$ score would be helpful for choosing an optimal treatment strategy, thus allowing a balance between cancer control and expected survival to prevent early death after treatment.

In conclusions, this study showed that there were no significant differences in OS, LRR, and DM between CCRT and $\mathrm{RT}$ alone treatment among elderly patients with stage 
III NSCLC; however, there was a poorer tolerance and higher incidence of acute esophagitis of grade 2 or higher in the CCRT group. Specifically, when the elderly patients had a $\mathrm{CCl}$ score of $\geq 5, R T$ alone seems to be favorable with a low probability of early death and equivalent clinical outcomes after treatment.

\section{Conflict of Interest}

No potential conflict of interest relevant to this article was reported.

\section{References}

1. Driessen EJ, Bootsma GP, Hendriks LE, et al. Stage III NonSmall Cell Lung Cancer in the elderly: Patient characteristics predictive for tolerance and survival of chemoradiation in daily clinical practice. Radiother Oncol 2016;121:26-31.

2. Sacher AG, Le LW, Leighl NB, Coate LE. Elderly patients with advanced NSCLC in phase III clinical trials: are the elderly excluded from practice-changing trials in advanced NSCLC? J Thorac Oncol 2013;8:366-8.

3. Atagi S, Mizusawa J, Ishikura $S$, et al. Randomized trial of thoracic radiotherapy with or without concurrent daily lowdose carboplatin in elderly patients with locally advanced non-small cell lung cancer (NSCLC): long-term follow-up of Japan Clinical Oncology Group (JCOG) study JCOG0301. J Clin Oncol 2017:35(15_Suppl):8532.

4. Atagi S, Kawahara M, Yokoyama A, et al. Thoracic radiotherapy with or without daily low-dose carboplatin in elderly patients with non-small-cell lung cancer: a randomised, controlled, phase 3 trial by the Japan Clinical Oncology Group (JCOG0301). Lancet Oncol 2012;13:671-8.

5. Dawe DE, Christiansen D, Swaminath $A$, et al. Chemoradiotherapy versus radiotherapy alone in elderly patients with stage III non-small cell lung cancer: a systematic review and meta-analysis. Lung Cancer 2016;99:180-5.

6. Miller ED, Fisher JL, Haglund KE, et al. The addition of chemotherapy to radiation therapy improves survival in elderly patients with stage III non-small cell lung cancer. J Thorac Oncol 2018;13:426-35.

7. Driessen EJ, Schulkes KJ, Dingemans AC, van Loon JG, Hamaker $M E$, Aarts MJ, et al. Patterns of treatment and survival among older patients with stage III non-small cell lung cancer. Lung Cancer 2018;116:55-61.
8. Sundararajan $V_{1}$ Henderson $T$, Perry $C$, Muggivan A, Quan $H_{1}$ Ghali WA. New ICD-10 version of the Charlson comorbidity index predicted in-hospital mortality. J Clin Epidemiol 2004;57):1288-94.

9. Ezer N, Smith CB, Galsky MD, et al. Cisplatin vs. carboplatinbased chemoradiotherapy in patients $>65$ years of age with stage III non-small cell lung cancer. Radiother Oncol 2014;112:272-8.

10. Harris JP, Murphy JD, Hanlon AL, Le QT, Loo BW Jr, Diehn M. A population-based comparative effectiveness study of radiation therapy techniques in stage III non-small cell lung cancer. Int J Radiat Oncol Biol Phys 2014;88:872-84.

11. Auperin A, Le Pechoux C, Rolland E, et al. Meta-analysis of concomitant versus sequential radiochemotherapy in locally advanced non-small-cell lung cancer. J Clin Oncol 2010;28:2181-90.

12. Fournel $P$, Vergnenegre $A$, Robinet $G$, et al. Induction or consolidation chemotherapy for unresectable stage III nonsmall-cell lung cancer patients treated with concurrent chemoradiation: a randomised phase II trial GFPC-IFCT 02-01. Eur J Cancer 2016;52:181-7.

13. Holgersson $G$, Sandelin $M$, Hoye $E$, et al. The value of induction chemotherapy for survival in patients with non-small cell lung cancer treated with radiotherapy. Anticancer Res 2012;32:1339-46.

14. Ardizzzoni A, Boni L, Scolaro T, et al. Induction chemotherapy followed by thoracic irradiation with or without concurrent chemotherapy in locally advanced inoperable NSCLC: a randomized phase III trial. J Clin Oncol 2008:26(15_ Suppl):7520.

15. Huang EH, Liao Z, Cox JD, et al. Comparison of outcomes for patients with unresectable, locally advanced non-small-cell lung cancer treated with induction chemotherapy followed by concurrent chemoradiation vs. concurrent chemoradiation alone. Int J Radiat Oncol Biol Phys 2007;68:779-85.

16. Luo H, Yu X, Liang N, Xie J, Deng G, Liu O, Zhang J, Zhang J, $\mathrm{Ge} H$. The effect of induction chemotherapy in patients with locally advanced nonsmall cell lung cancer who received chemoradiotherapy: a systematic review and meta-analysis. Medicine (Baltimore) 2017;96:e6165.

17. Soto-Perez-de-Celis E, Li D, Yuan Y, Lau YM, Hurria A. Functional versus chronological age: geriatric assessments to guide decision making in older patients with cancer. Lancet Oncol 2018;19:e305-e316. 